Papers and Proceedings of the Royal Society of Tasmania, Volume 118, 1984

(ms. received 2.II.1983)

\title{
A MIDDEN EXCAVATION - ROYAL TASMANIAN BOTANICAL GARDENS, HOBART
}

by A.R. Kerrison and M.A. Binns

University of Tasmania and St James College, Cygnet

(with three tables, five text-figures and one plate)

ABSTRACT

KERRISON, A.R. and BINNS, M.A., 1984 (31 viii): A midden excavation - Royal Tasmanian Botanical Gardens, Hobart. Pap. Proc. R. Soc. Tasm., 118: 53-64, pl. 1.

https://doi.org/10.26749/rstpp.118.53 ISSN 0080-4703. Centre for Education,

University of Tasmania, Hobart, Tasmania, Australia.

Radiocarbon analysis of charcoal taken from the base of a midden located within the Royal Tasmanian Botanical Gardens, Hobart, indicates that first occupancy of this site occurred some 5000 years ago. The mussel Mytilus edulis planulatus provided the bulk of the shellfish diet which may have been supplemented with a number of small species including the gastropods Bembicium auratum and Austrocochlea constricta zebra. A feature of this site is the relatively rich supply of petrologically diverse stone artefacts. This is at variance with the general pattern for middens previously excavated in the Derwent River estuary. Also present are small, round, hard pebbles, a feature not previously reported from similar sites on the Derwent River. Scanning electron microscopic analysis of charcoal indicates that the she oak Casuarina stricta provided some of the wood fuel for fires at this site.

\section{INTRODUCTION}

Surface scatter of shell and charcoal in the northern corner of the Royal Tasmanian Botanical Gardens, herein "the Gardens", plus an exposed section in a nearby road cutting, indicated the possibility of finding a relatively intact aboriginal midden inside the Gardens' boundaries. Site development of such a midden would enhance the educational and informational roles played by the Gardens. An excavation was made to ascertain the degree of disturbance of the midden and generally to test the feasibility of open site development. This report details findings obtained from this initial excavation.

\section{LOCATION}

The Gardens are located in the Queens Domain, which is a public parkland situated on the west bank of the Derwent River some $2 \mathrm{~km}$ from the central business district of Hobart (fig. 1). There are numerous middens in and around the Gardens. Evidence of shell and ash, consistent with aboriginal middens, is readily discernible in the general area.

\section{PERSPECTIVE}

Possibly the earliest published reference to these middens was made by Gunn (1846) who drew attention to

"... the immense quantity of comminuted shells, mixed in the soil of certain portions of Government Gardens, at Hobart Town ..."

Archaeological studies and excavations undertaken within the Derwent estuary have been summarized by Stockton \& Wallace (1979). Some seven studies of various kinds had been reported by that date. Since then reports have been made by Lister (1979), Officer (1980), and Gaffney \& Stockton (1980). Officer (1980) located, mapped, and briefly described the middens, quarry sites and rock shelters along the shores of the estuarine Derwent from New Norfolk to a line connecting Blinking Billy Point to Tryworks Point (fig. 2). In all, he recorded 416 she11 middens (118 on the west bank of the Derwent and 298 on the east), and eleven quarry or tool manufacturing sites. 


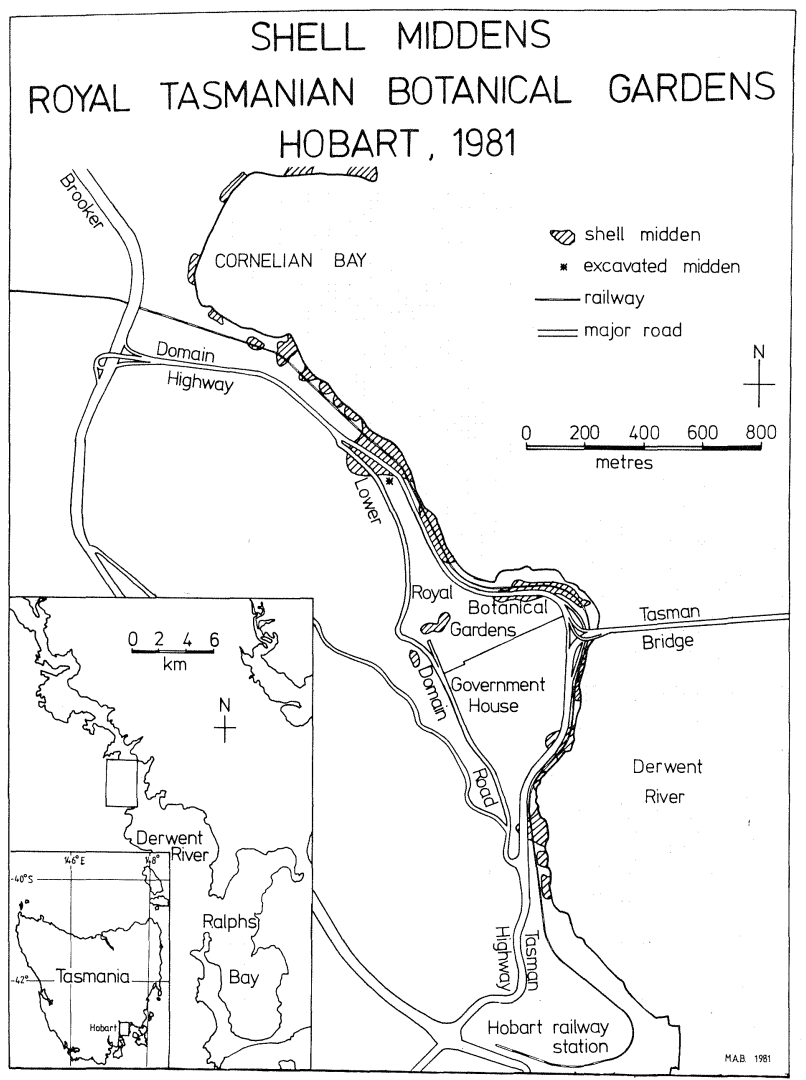

FIG. 1 - Map showing the location of middens in and around the Royal Tasmanian Botanical Gardens .

European settlement in the general area has undoubtedly destroyed, or buried, numerous middens and aboriginal quarries and thus the true density of such sites would certainly be higher than shown.

\section{EXCAVATION METHOD}

Excavation of the Gardens midden commenced during August, 1980. A pit was opened up close to a footpath and a highway cutting. This site was abandoned as it soon became obvious that severe dislocation of the midden material had occurred, presumably during the road and footpath construction.

A second excavation was then undertaken on a mound some 30 metres south of the first site. This pit was one metre square and spit depths were $50 \mathrm{~mm}$. All material was sieved using a $6 \mathrm{~mm}$ mesh. All cultural material was collected including all shell which had been retained by the sieve.

The top spit contained such foreign matter as railway clinker, ring tops from drink cans and cigarette butts. It appeared from Spit 2 onwards that in this location the midden was stratified and had not suffered dislocation. However, during laboratory analysis of sieved material two pieces of bone from Spit 5 were identified as belonging to the rabbit or hare (Dr P. Murray, pers. comm.) which means that some recent contamination of the midden, at depth, has occurred. The western section of the pit (fig. 4) exhibits a feature resembling an infilled rabbit burrow. No other features indicating contamination or disturbance were noted during the excavation. 


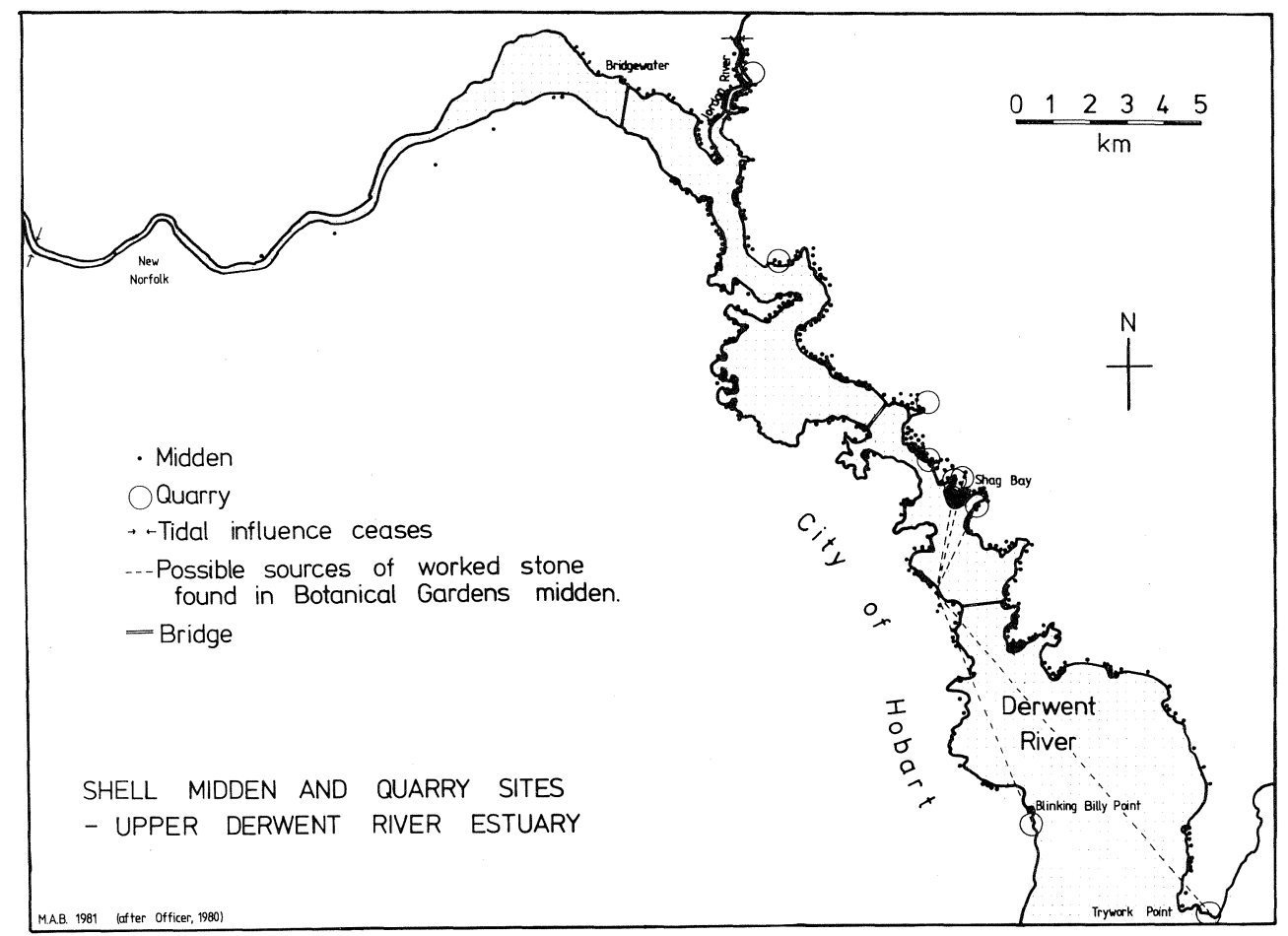

FIG. 2 - Map showing the location of middens and quarries in the middle and upper Derwent River Estuary.

Charcoal in Spits 1,2 and 3 was in a powder form and not retained by the sieve but was collected regularly from Spit 4 onwards.

From Spit 6 (that is, from a depth of $0.3 \mathrm{~m}$ ) normal, on-site sieving had to be abandoned due to the changed nature of the midden matrix. The midden material had been bonded by clay. Decomposing dolerite, the country rock in this area, is presumably the source of the clay.

All material from Spits 6 to 11 was bagged and transferred to a laboratory for analysis. Considering the large volume of material that had now to be treated elsewhere it was also decided to excavate only half the pit from Spit 9 onwards. Thus Spits 9, 10, 11 were $1 \times 0.5 \times 0.05 \mathrm{~m}^{3}$ in volume. Spit 11 reached a sterile base and excavation was terminated.

The material from Spits 6 to 11 was treated as follows. Each bag was opened into the $6 \mathrm{~mm}$ sieve. The contents were washed to remove the clay and the sieve residue was then dried and re-bagged. The material from all spit levels, that is all the material retained by the sieve, was then analysed using the following procedure.

1. The total mass of all shell for each spit was found and the percentage mass for each species component was calculated. The number of shells in each species component was also counted when it was possible to do so. For mussel, which is generally in a crushed state throughout the midden, the umbos were counted and divided by 2 , but for oyster the only reasonable comparison between spits was to compare mass. 
2. The stone flakes were separated and labelled according to spit level as were the pebbles found throughout the midden.

3. All ochre was collected.

4. Charcoal samples from Spit 4 onwards were collected on site, where possible, or from the washed residue.

SHELL

The musse1 Mytilus edulis planulatus is dominant throughout the midden. The percentage mass ranges from $96.9 \%$ in Spit 1 to $99.5 \%$ in Spit 11 (fig. 3). By contrast the mud oyster Ostrea angasi is much less important as a food source at this site. The considerable shell bulk of Ostrea gives a percentage mass value which, if equated with food value, is obviously inflated. The shell weight of one medium-sized mud oyster with a dorsoventral length of $80 \mathrm{~mm}$ is approximately 70 grams. By contrast, the shell of a good-sized mussel of near $70 \mathrm{~mm}$ weighs approximately 15 grams. Thus, when percentage mass of shell for different species is compared (fig. 3) it must be remembered that one or two fragments of Ostrea shell may constitute a whole percentage point.

From midden sites further up the Derwent estuary the mussel Xenostrobus securis has been recorded (Gaffney \& Stockton 1980). It appears that X. securis occurs in localities where permanent supplies of fresh water are found entering the system. Indications are that the Xenostrobus:Mytilus ratio at a site may be a valuable environmental indicator since any change in the supply of fresh water results in a consequent change in the Xenostrobus:Mytilus ratio. Xenostrobus securis was not recorded in the Gardens midden. At the present time there are no permanent supplies of fresh water entering the Derwent in the immediate vicinity of the midden. The complete absence of $X$. securis indicates that this situation prevailed during the period of Aboriginal occupation of the site.

An alternative hypothesis is that Mytilus was a preferred food source over Xenostrobus. This appears unlikely given that the morphological differences between the two species are very slight, making selective collecting extremely difficult.

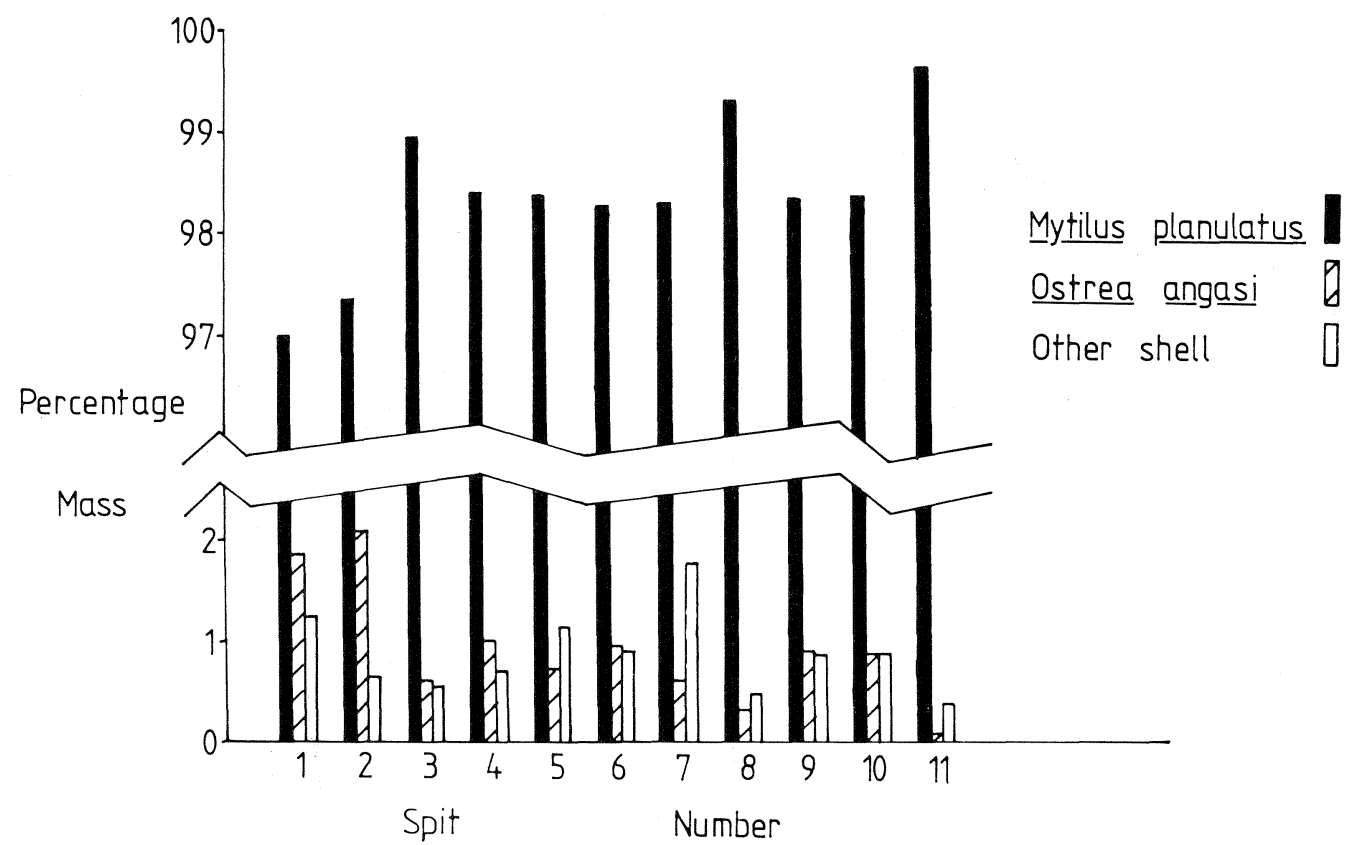

FIG. 3 - Percentage mass of component shell for each spit level. 
A.R. Kerrison and M.A. Binns

Apart from Mytilus and Ostrea the remaining shel1, classified as "Other Shel1" in fig. 3, makes up one or two percent of the shel1 mass for any one spit level. Of this "Other Shell" the small coiled gastropods Bembicium auratum and Austrocochlea constricta zebra are the most numerous and persistent, being present in each spit level. The apexbase length of these shells rarely exceeds $12 \mathrm{~mm}$. The small pelecypods Venerupis crenata and $V$. diemenensis may have been exploited for food, although the dorso-ventral height, for both species, rarely exceeds $20 \mathrm{~mm}$.

The significance of these small shells in the midden is conjectural. It is not clear whether the gastropods and pelecypods mentioned above contributed to the food supply or were incidental to the gathering of mussel. It is possible that they were collected along with the mussel but perhaps not deliberately, but once collected became part of the food supply. There is evidence from work done elsewhere in Tasmania (Vanderwal 1978) that, on occasions, numerous species were collected for food and the size of the shell seems not to be an altogether important factor. Indeed, many of the Mytilus specimens from the Gardens midden are very small, overall dorso-ventral length quite often being as 1 ow as $25 \mathrm{~mm}$.

The land snail Caryodes dufresnii is present throughout the midden but, as shown in table 1, it becomes more prominent towards the top of the midden. The shell of this snail is quite fragile yet is usually found complete. This is in direct contrast to the crushed and burnt nature of the mussel she11. It seems that Caryodes invaded the midden during those periods when the midden site was unused.

Attempts to use the minor shells as environmental indicators were unsuccessful. This was primarily due to the lack of conclusive information on their environmental significance in the Derwent River. Another aspect of this problem is the possibility of selective rather than incidental collection of minor shells.

TABLE 1

COMPONENT SHELL NUMBERS FOR EACH SPIT LEVEL

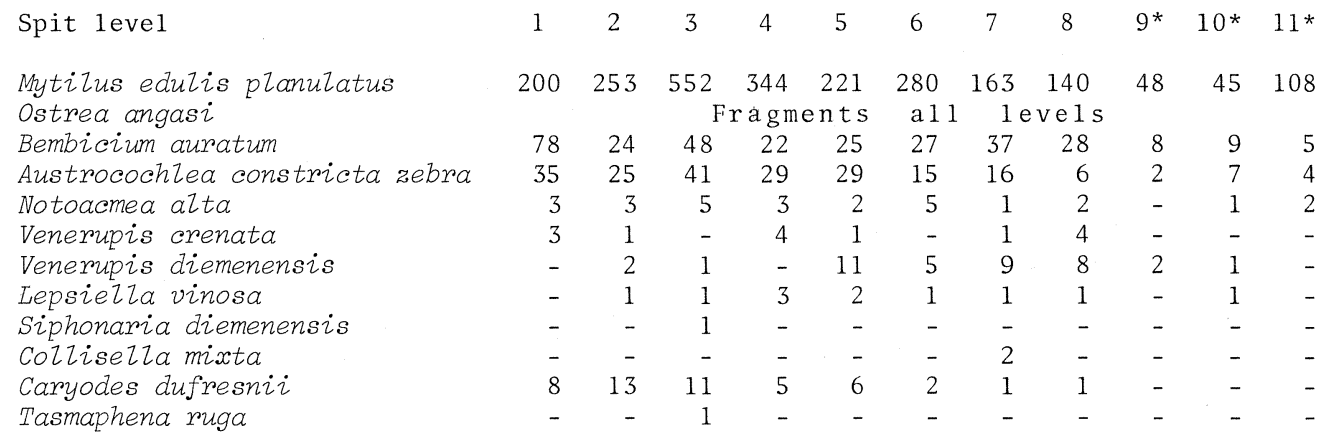

* Spits 9, 10, 11 are half volume spits.

\section{SHELL DISTRIBUTION AND MIDDEN PROFILE}

The total depth of shell in this pit is $0.55 \mathrm{~m}$. Distinct horizons of shell were encountered during excavation with the principle concentration occurring between 0.1 and $0.2 \mathrm{~m}$. below the surface. This depth coincides with Spit levels 3 and 4 (see fig. 3 and table 1). At these levels an uninterrupted band of closely packed mussel was found. Relatively high concentrations of Bembicium and Austrocochlea also occur at this level. It was noted that in the northern corner of the pit the mussel shells were layered in such a manner that layers made a distinct angle with the horizontal (fig. 4). 


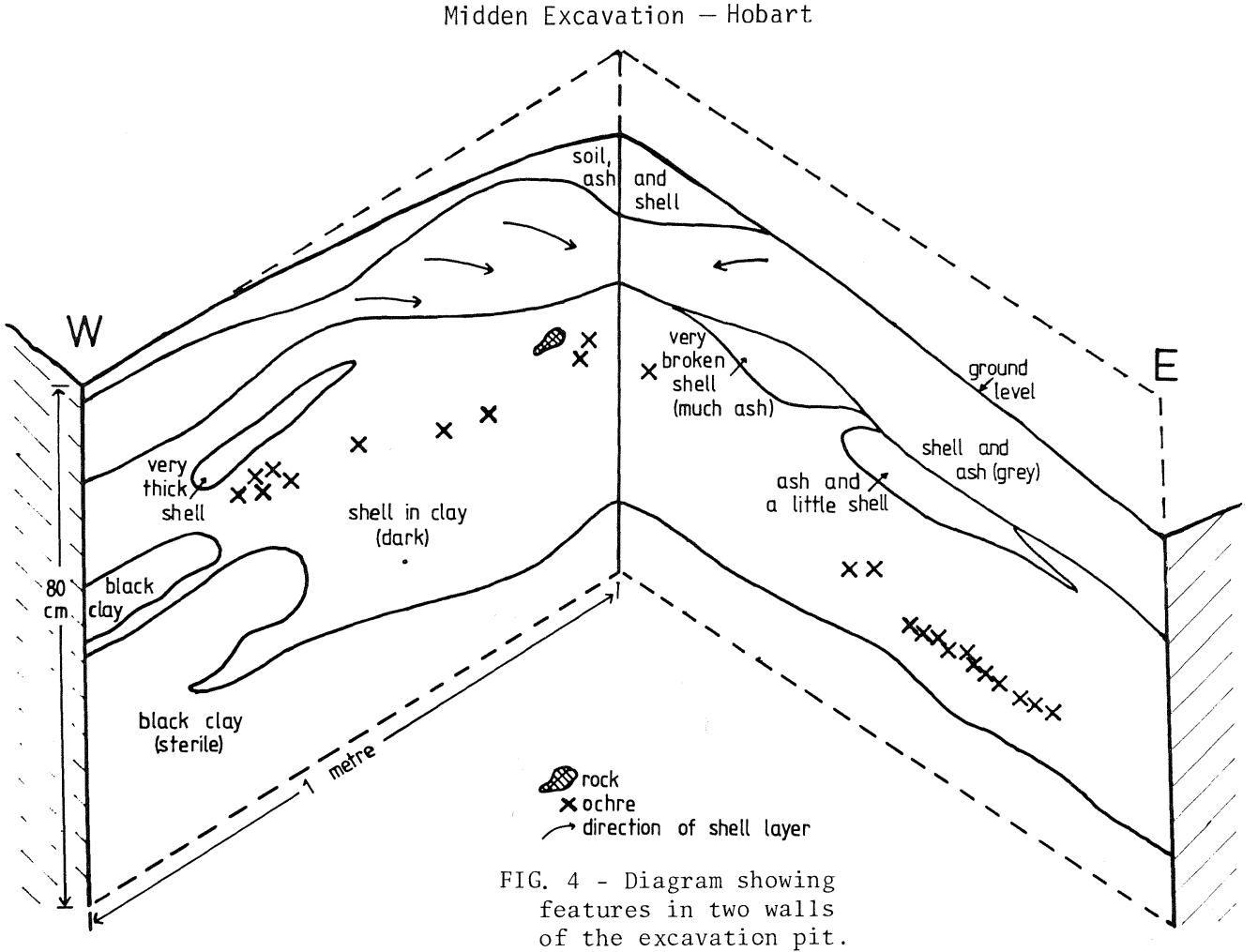

Beneath Spits 3 and 4 shell concentrations occur but only as pockets, as can be seen in fig. 4. The shell counts never reach the same high levels as occur in Spits 3 and 4 . It is of interest to note that with depth there is an overall decrease in the number count of the minor shells. This seems to be a real rather than apparent change. The possible reasons could be selectivity in collection, environmental changes or shell fragility. However, fragility and consequent crushing would not seem to be a major factor because of the inherent structural strength of most of the minor shells, and the lack of discernible change, with depth, in the fragmentation of Mytilus.

STONE

Dolerite boulders of various sizes and a variety of hard, silica-rich stone flakes and pebbles were extracted from the midden.

The dolerite was in the form of assorted lumps, commonly of cobble size (64-256 mm), weathered and usually in a disintegrating state. The inclusion of this rock within the midden may, in part, be accounted for by local geology, the Queens Domain and areas surrounding the Gardens being primarily composed of dolerite. However, the rock was found at all levels within the midden, and not merely basal, implying at least some purposeful introduction.

The purpose for which the dolerite was used remains unclear. The texture and fracturing qualities of this rock are such that it is of little value in producing implements with fine edges. No juxtaposition patterns, or associations, for the rock were noted during the excavation. Evidence of charring, which could be expected if some of the rock had been used as hearth surrounds, was absent. This, in turn, could be explained by the very weathered nature of much of the dolerite which would obliterate evidence of charring. 
PEBBLES

In the main the pebbles have an exotic petrology. They are typical of the pebble dropstones found in local Permian sediments and this is the most likely source. The pebbles may be found loose on rocky foreshore stretches of the Derwent such as occur in the Gardens area where they may be found today. The conclusion that the aborigines actually collected the pebbles from in front of the Gardens has to be tempered by the fact that middens are being undercut and slumping into the Derwent all along the waterfront in the Gardens area. The pebbles there today may actually be coming fron the eroding middens.

Table 3 shows a clustering of pebbles and flakes and the pebbles were probably used during the preparation and repair of the stone flakes. Many of the flakes in Spits 4 to 11 , where the pebbles also occur, are small and fine (table 2). The pebbles may have been used as minute hammer stones or for delicate pressure application during flake and edge preparation.

\section{FLAKES AND PEBBLES}

Eighty-one pieces of very hard stone of various petrological types were also extracted. Of this number 21 pieces are hard pebbles and the remaining 60 pieces are flakes produced during the manufacture or repair of stone tools.

The 60 flakes were divided into two groups. Group One has 11 pieces which show clear evidence of some edge preparation or use wear. Figure 5(a) (b) (c) are examples from this group. The remaining 49 flakes constitute Group Two. These flakes show no edge preparation but clearly have been removed by force from cores of stone.

Table 2 gives information on dimensions and mass of Group One and Two flakes and the pebbles.

Table 3 shows the distribution of all flakes and pebbles through the midden. Petrological composition, derived from hand lens examination, is also shown and, where possible, source localities are given for the rock types. Petrological composition of both flakes and pebbles varies widely. The most common stone includes various quartz hornfels, chalcedonic rock and finegrained basalts. Examination reveals that hornfels have been formed from a variety of sediments including well-sorted siltstones and sandstones, poorly-sorted sandstones, sandstones with clay, and siltstones with fossils (Permian). Local geology would indicate that original deposits were most likely of Tertiary, Triassic and some certainly of Permian age. Also present, and more exotic in nature, are two pieces of what appear to be fine-grained granite, a piece of sheared quartzite, pieces of devitrified volcanic glass and a piece of schistose quartzite.

The chalcedonic rocks almost certainly come from the Sandy Bay volcanic complex which is some $7 \mathrm{~km}$ down river from the Gardens. Pinpointing the other rock sources is much more difficult. The geology of the Hobart area is such that there are numerous igneous-sedimentary contacts. Jurassic dolerite intruded Triassic

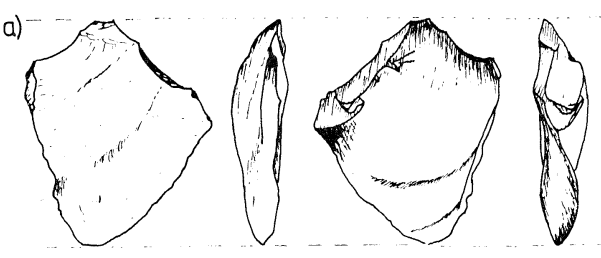

\section{b)}
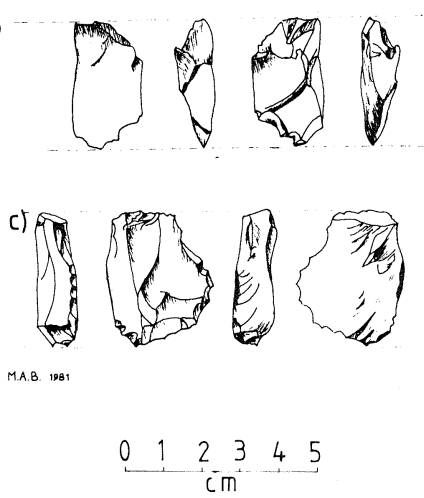

FIG. 5 - Examples of the stone tools extracted from the Gardens midden. and Permian sediment giving rise to a wide variety of hornfelsic rocks. Later, Tertiary sediments were baked in many places by Tertiary basalts. Thus, a variety of rock suitable for tool making is to be found in and around Hobart (Sutherland 1972). Locating the 
exact sources of the hornfelsic rocks found in the Gardens midden would in most instances be extremely difficult. The quartzitic rocks and the granites are certainly not of local origin. However, it cannot be concluded that these and other exotic rocks were traded or carried into the Hobart area. Dropstones, or "erratics", of a diverse petrological nature occur in Permian sedimentary outcrops in and around Hobart. This factor complicates the study of trade or importation of stone into the area. Some of the more probable source localities for the midden stone are shown in fig. 2. Detailed information on these and other quarry sites within the Derwent, and in the State generally, was given by Sutherland (1972).

\section{TABLE 2}

FLAKES AND PEBBLES: LINEAR DIMENSIONS AND MASS

$\begin{array}{lccc} & \text { Mean } & \text { Mode } & \text { Range } \\ \begin{array}{l}\text { FLAKES } \\ \text { Group I }\end{array} & & & \\ \text { length } & 32 & 25 & 16-50 \\ \text { width } & 24 & 20 & 11-45 \\ \text { height } & 10 & 8 & 4-12 \\ \text { mass } & 8.1 & 3.4 & 1.1-26.5 \\ \text { Group 2 } & & & \\ \text { length } & 23 & 15 & 10-40 \\ \text { width } & 16 & 12 & 8-40 \\ \text { height } & 7 & 5 \& 9 & 0.2-16.1 \\ \text { PEBBLES } & & & \\ \text { length } & 21 & 18 & 10-40 \\ \text { width } & 15 & 13 & 7-36 \\ \text { height } & 9 & 5 & 4-19 \\ \text { mass } & 4.8 & 1.0 & 0.6-27.2 \\ & & & \end{array}$

Dimensions in millimetres; mass in grams.
The diversity of stone type combined with the relative abundance of flakes were features not expected of this site. The number of flakes extracted from recorded excavations on the Derwent is given below: Alum Cliffs (Stockton \& Wallace 1979): 2 flakes.

Fishers Hill (Stockton \& Wallace 1979) two pits: 0 and some (?) flakes. Shag Bay Rock Shelter (Vanderwal 1977): 2 flakes,

Jordan River (Gaffney 1978): 7 flakes. By contrast, the Gardens midden gave 60 flakes.

Petrological diversity is also unique to this midden. The only similar situation in this regards is to be found at the Risdon Cove Historic Site (Lister 1979) which is some $5 \mathrm{~km}$ upriver from the Gardens and on the opposite bank. However, this is not a midden and is described as a specialized stone tool site.

OCHRE

Pellets of ochre were recovered from all levels. Concentrations occurred in Spits 4 and 5 where 46 and 39 pieces respectively were collected. By contrast the next highest count occurred in Spit 2 (16 pieces) with counts never exceeding 10 pellets for any other spit. Concentrations of ochre can be seen in the walls of the excavation as is shown in fig. 4 .

Most of the ochre is yellowish-brown in colour, gritty to the feel and most commonly of diameter $10 \mathrm{~mm}$ or less. Occasionally pieces of more reddish ochre were found. To the authors' knowledge no ochre quarry has been reported in this general area. This would account for the general lack of quality in the ochre which, in the main, appears to be a weathering product of local rocks.

\section{CHARCOAL - RADIOCARBON DATE}

Charcoal and charcoal powder darkens the entire midden. Collection commenced at Spit 4 higher charcoal being powdery or minute, and fine enough to pass through the sieve. Lighter patches of grey ash mark possible hearth locations (fig. 4). Radiocarbon dating analysis was undertaken on a 3 gm mass of charcoal extracted from base level material. Results obtained give a first occupancy date for the midden of $5210 \pm 110$ years BP (Beta5099). This date is consistent with basal dates obtained within the Derwent estuary (Stockton \& Wallace 1979). After a glacial low at around 20000 years BP the climate became warmer resulting in rising sea levels. By 5-6 000 years BP the sea appears to have reached a level very near that of the present day. Marine shellfish colonized flooded 


\section{A.R. Kerrison and M.A. Binns}

TABLE 3

PETROLOGICAL DISTRIBUTION OF FLAKES AND PEBBLES - BOTANICAL GARDENS MIDDEN

Rock Type

Hornfels: grey, poorly-sorted clay sediments

Hornfels: light grey, medium sorting

Hornfels: grey, fine-grained

Contact metamorphosed Permian siltstone

Basalt: fine-grained

Hornfe1s: brown, fine-grained

Hornfels: pink, poorly-sorted

Hornfels: silver/grey, medium- to fine-grained

Hornfe1s: grey, thinly-bedded, fine-grained

Chal cedony

Jasper/chalcedony

Hornfels: pale yellow, fine-grained

Silicified breccia

Devitrified volcanic glass

Schistose quartzite

Granite: grey

Sheared quartzite

Granite or arkose: brown, fine-grained

Granite or aplite: white

Silicified sandstone: red, poorly-sorted

Quartz

Hornfels

Permian sandstone

Baked mudstone: brown/pink

Flakes: unidentified assortment

Source F P Spit Level

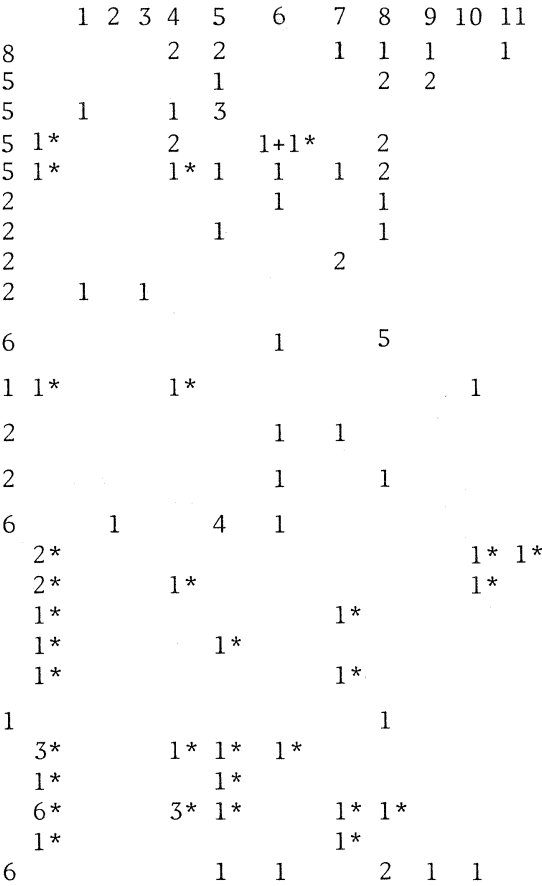

Source: A - exact location unknown, but petrology indicates Hobart area; B - Sandy Bay; C - probably Shag Bay; D - probably near Tryworks Point; E - unknown, but not Hobart area; F - unknown.

Note: Spits 9, 10, 11 - half volume spits. $F=$ flakes. $P$ = pebbles. * = pebbles.

valleys, such as the Derwent, and Aboriginals exploited this food source. Middens with older basal dates would have been closer to older, and thus lower, shorelines. Rising seas would have inundated and most likely destroyed such middens. Thus, basal dates for middens in the Derwent estuary reflect most recent high sea levels, given that Aboriginal occupancy of the continent occurred within the last 50000 years. Within this time span sea levels have been lower than those of the present (Orchiston 1979).

\section{Charcoal Micrographs}

Charcoal samples from Spits $4,6,8$ and 10 were subjected to electron probe microanalysis using a scanning electron microscope (McGinnes, Harlow \& Beall 1976). Micrographic sections revealing cellular structure were obtained. By comparing these with micrographs of known samples it was hoped to identify the species of tree from which the charcoal had been derived. Good micrographs were obtained for charcoal samples taken from Spits 6 and 10. The evidence suggests that at these levels wood from the she oak Casuarina stricta was used as a fuel for fires (plate 1). These trees are growing in the vicinity of the midden today.

It would seem that electron microprobe analysis of charcoal could be of benefit in archaeological investigations of aboriginal sites. With controlled charcoal sampling at each spit level, combined with electron microscopy, it may be possible to establish an overview of fuel collecting habits during the occupancy of a particular site. 


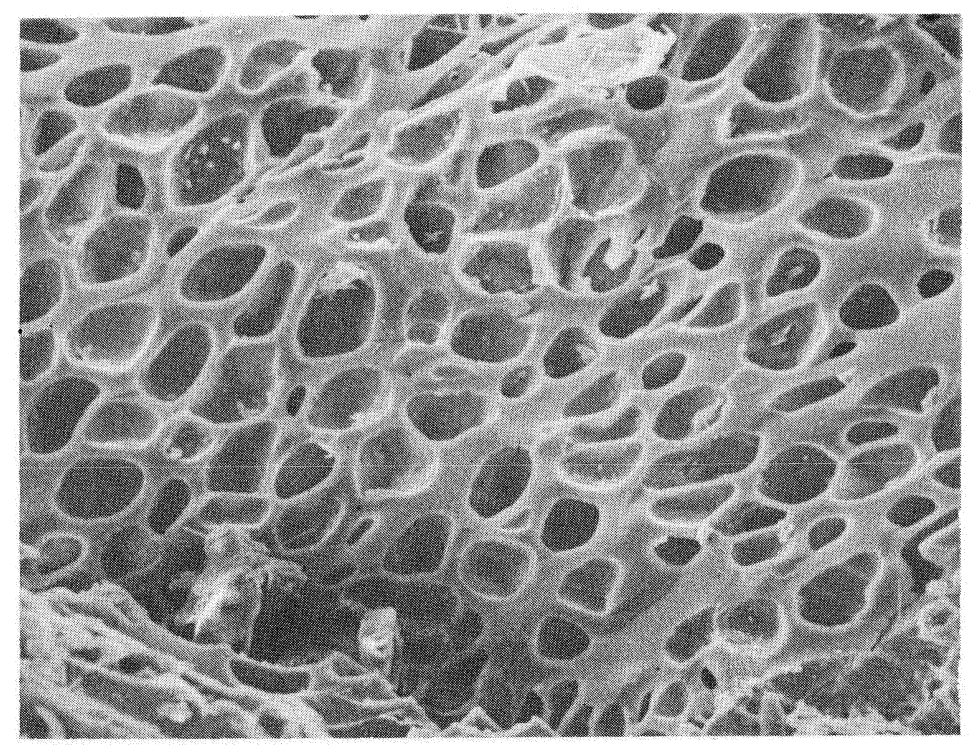

Plate 1 - Electron micrograph of a charcoal sample taken from Spit 6. Mag. $\times 300$. The cellular structure as shown indicates that the sample is charcoal from the she oak Casuarina stricta.

BONE

The only bone to be positively identified as such and be retained by the sieve came from Spit 5. Two pieces of mammal bone have been identified as a patella, which has a maximum dimension of $8 \mathrm{~mm}$, and the epiphysis of the tibia, maximum dimension $18 \mathrm{~mm}$. The most likely source is the rabbit or hare (Dr P. Murray, pers. comm.) which means that some post-European contamination of the midden, at depth, has occurred.

\section{SUMMARY AND DISCUSSION}

Generalizing from the available archaeological evidence the features that Derwent River middens exhibit may be summarized as follows. The middens usually have:

(i) a depth of between 0.5 and $1.0 \mathrm{~m}$,

(ii) shell content composed primarily of mussel, some oyster and a variety of smaller species,

(iii) a small number of stone artefacts,

(iv) a minimal or zero bone content,

(v) ochre present as small pellets,

(vi) assorted lumps of local rock,

(vii) charcoal, hearths and distinct layers of shell, and

(viii) basal dates of some 5000 years BP.

In the Gardens midden only (iii) - the number of stone artefacts - has shown a marked deviation fron the general pattern.

Derwent River middens may be seen as examples of single resource utilization. The absence of bone supports this view. The scarcity of stone artefacts may be 1 inked to the lack of need for stone tools when gathering and eating shellfish. In this sense the Gardens midden is atypical for here there is a comparatively high incidence of stone artefacts. A possible explanation for this situation may be linked to the general smallness of the flakes and the range of their petrology.

On the opposite shore of the Derwent the middens, with their low flake content, are in close proximity to quarries (fig. 2) or the specialized stone tool site (Lister 1979). Procurement of suitable stone would not require lengthy travel. There is also evidence to show that flakes were fully prepared at the quarry sites. For example, the paddocks sur- 


\section{A.R. Kerrison and M.A. Binns}

rounding the quarry near Tryworks Point (fig. 2) are littered with chips of the quarried silicified breccia and rounded, cobble-sized hammer stones. Similarly at Oyster Cove, in the D'Entrecasteaux Channel south of Hobart, Winter (1976) counted millions of waste flakes associated with the quarried silcrete outcrop.

The Gardens midden is, by contrast, remote from the nearest known quarry. Suitable stone and flakes would need to be conserved with manufacture and repair being carried out at the midden. In these circumstances repair of flakes would be important, thus explaining the need for small pebble hammer stones and the consequent smaller flakes found in this midden. The lack of a nearby single source of rock would also account for the wide petrological diversity.

This interpretation may not be applicable to the whole midden. The pattern of occupancy postulated above does not fit well with the evidence from the topmost three spits where no pebbles and only four flakes were found (table 3).

If site development of the Royal Botanical Gardens midden takes place in the future the extended excavation would provide further information on the occupancy pattern. It would also help clarify the context and relationship of this midden to others in the Derwent area.

\section{ACKNOWLEDGEMENTS}

We wish to thank Dr M.R. Banks, University of Tasmania, and Dr D.C. Green, Mines Department, for their help in petrological identification; Mrs E. Turner, Tasmanian Museum and Art Gallery, for her help in shell identification and information on particular shell habitats; Mr D. Ransom, National Parks and Wildlife Service, for his help in some stone tool identification; Mr I. Bailey for his help in field and 1aboratory work; Mr A. Goede, University of Tasmania, for directing our attention to the possibilities in the use of electron micrographs of charcoal and for allowing us to compare our results with his collection of charcoal micrographs of Tasmanian flora; Dr P. Murray, formerly of the Tasmanian Museum and Art Gallery, for his identification of bone pieces; and to the Tasmanian Archaeological Society for financial assistance in relation to radiocarbon dating.

\section{REFERENCES}

Gaffney, L., 1977: Jordan River Midden Excavation. Tasm. Coll. Adv. Educ., B.Ed. dissertation, unpub. (now Univ. Tasm. Centre for Educ.).

\& Stockton, J., 1980: Results of the Jordan River midden excavation. Australian Archaeology, 10: 68-78.

Gunn, R.C., 1846: On heaps of recent shells which exist along the shores of Tasmania. Tas. J. Nat. Sci. Agric. Stats. etc., 2: 332-336.

Lister, A., 1979: Archaeology of Risdon Cove Historic Site 1978/79 Part III. National Parks and Wildiife Service, Tasmania, unpub. report.

McGinnes, E.A., Harlow, C.A. \& Beall, F.C., 1976: Use of scanning electron microscopy and image processing in wood charcoal studies. Scanning Electron Microscopy/1976/11, VII: 543-548.

Officer, I., 1980: Survey of Derwent River Aboriginal midden and quarry sites. Tasm. Coll. Adv. Educ., B. Ed. dissertation, unpub. (now Univ. Tasm. Centre for Educ.).

Orchiston, D.W., 1979: Pleistocene sea level changes, and the initial Aboriginal occupation of the Tasmanian region. Mod. Quatemary Res. S.E. Asia, 5 (1979): 91-103.

Stockton, J. \& Wallace, A., 1979: Towards a human prehistory of the lower Derwent River area, south-eastern Tasmania, Australia. Pap. Proc. R. Soc. Tasm., 113: 81-84.

Sutherland, F.L., 1972: The classification, distribution, analysis and sources of materials in flaked stone implements of Tasmanian Aborigines. Rec. Queen Vic. Museum No. 42 .

Vanderwal, R.L., 1978: Pre-history and the archaeology of Louisa Bay. In Gee, H. \& Fenton, J. (eds): THE SOUTH WEST BOOK - A TASMANIAN WILDERNESS: 17-21. Australian Conservation Foundation, Melbourne, 1979.

Winter, N.D., 1976: Tasmanian Aboriginal quarries and resources at Oyster Cove. Tasm. Colz. Adv. Educ., B. Ed. dissertation, unpub. (now Univ. Tasm. Centre for Educ.). 